\title{
Hour Times Femtomole per Milliliter
}

National Cancer Institute

\section{Source}

National Cancer Institute. Hour Times Femtomole per Milliliter. NCI Thesaurus. Code C85612.

Hours times femtomoles per milliliter. 